matosus. A similar case of Sjögren syndrome and subsequent development of systemic lupus erythematosus has been reported in a 12 year old boy. ${ }^{3}$ In our patient, two points remain to be clarified, whether the seizures were the first symptom of systemic lupus erythematosus central nervous system involvement and whether any relation can be found between the phenobarbitone treatment and the onset of systemic lupus erythematosus.

Interpretation of sequential renal biopsies. The first renal biopsy showed notable interstitial lymphoplasmocytic infiltrate without glomerular alteration. Similar features have been reported in Sjögren syndrome, ${ }^{4}$ but in some cases of systemic lupus erythematosus, where interstitial lymphocytic infiltrate has been found on renal biopsy, ${ }^{5}$ the initial nephropathy worsened and rapidly progressed to renal failure. ${ }^{6}$ On the second renal biopsy a mild diffuse proliferative nephritis typical of systemic lupus erythematosus was found, but the interstitial lymphocytic infiltrate persisted. Thus, the sequential renal changes in our patient may have been those of systemic lupus erythematosus, with lym- phocytic interstitial infiltrate at the beginning, progressing to the typical glomerular lesions.

We thank Mrs F Danon (Paris) for the anti-SSB test, Dr Lambert (Geneva) for the Clq binding test, and Mr Ragonnaud for the photographs.

\section{References}

${ }^{1}$ Chudwin DS, Daniels TE, Wara DW, et al. Spectrum of Sjögren syndrome in children. $J$ Pediatr 1981;98:213-7.

2 Tarpley TM, Jr, Anderson LG, White CL. Minor salivary gland involvement in Sjögren's syndrome. Oral Surg 1974;37:64-74.

${ }^{3}$ Romero RW, Nesbitt LT, Jr, Ichinose H. Mikulicz disease and subsequent lupus erythematosus development. JAMA 1977;237:2507-10.

4 Tu WH, Shearn MA, Lee JC, Hopper J, Jr. Interstitial nephritis in Sjögren's syndrome. Ann Intern Med 1968;69:1163-70.

5 Washington University School of Medicine. Clinicopathological conference. Interstitial nephritis in a patient with systemic lupus erythematosus. Am J Med 1980;69:775-81.

6 Cunningham E, Provost T, Brentjens J, Reichlin M, Venuto RC. Acute renal failure secondary to interstitial lupus nephritis. Arch Intern Med 1978;138:1560-1.

Correspondence to Dr J B Palcoux, Clinique Médicale Infantile, Hotel-Dieu, BP69, 63003 Clermont-Ferrand, France.

Received 13 October 1983

\title{
Systemic carnitine deficiency exacerbated by a strict vegetarian diet
}

\author{
A ETZIONI, J LEVY, M NITZAN, P ERDE, AND A BENDERLY \\ Department of Pediatrics 'A', Rambam Medical Center and Faculty of Medicine, Technion-Israel Institute of \\ Technology, Haifa, and Department of Pediatrics 'A', Beilinson Hospital, Tel Aviv University Medical \\ School, Tel Aviv, Israel
}

SUMMARY A 12 year old boy suffered episodes of vomiting, lethargy, and hypoglycaemia from the age of 1 year. Adhering to a vegetarian diet caused an increase in frequency and severity of the attacks. It was found that he was suffering from systemic carnitine deficiency that responded promptly to treatment with L-carnitine.

Carnitine deficiency, first described in $1973,{ }^{1}$ can manifest itself in two forms-myopathic and systemic. $^{2}$ In myopathic carnitine deficiency, carnitine concentrations are reduced only in muscle, but in the systemic form, carnitine concentrations are reduced in several tissues, and plasma concentrations are also reduced. The patients often present in infancy with features resembling Reye's syndrome, (encephalopathy, fatty liver, raised hepatic en- zymes, and hypoglycaemia). Recently, dietary dependent carnitine deficiency has been described. ${ }^{3}$ We report a child with systemic carnitine deficiency that was aggravated by a strict vegetarian diet. treatment with L-carnitine resulted in a dramatic improvement.

\section{Case report}

The patient, who is now 12 years old, was first evaluated at the age of 3 years. He was born after a normal pregnancy and delivery to healthy parents. His birthweight was $3.2 \mathrm{~kg}$. At the age of 1 year he suffered his first episode of vomiting and lethargy, and low serum glucose values were noted. He was treated with intravenous glucose and was discharged after three days. Since then similar episodes occurred every few months. When first evaluated at our hospital a blood glucose of $20 \mathrm{mg} / \mathrm{dl}(1 \cdot 1 \mathrm{mmol} / \mathrm{l})$ 
and raised hepatic enzymes were noted during an acute attack. The urine was positive for ketone bodies. He was stuporous on admission but responded to glucose administration and after two days stopped vomiting. His weight and height were at the 25th centile, and his psychomotor development was normal. Investigations for hypoglycaemia were negative, and he was discharged home with the presumptive diagnosis of ketotic hypoglycaemia of infancy.

Over the subsequent years he was admitted to hospital every four to five months with similar episodes that clinically resembled Reye's syndrome. On no occasion were ketone bodies found in the urine, despite the hypoglycaemia. His development proceeded normally and at that time muscle weakness was not noted. At the age of 10 years he experienced only one episode during the year, but became a vegetarian and refused to eat meat. Two months later he had a further episode of vomiting, lethargy, liver enlargement, and hypoglycaemia, and from that time his condition deteriorated. The frequency of attacks increased to one every three weeks and he started to complain of muscle weakness.

In October 1982 he was again admitted to hospital, and when his condition improved, plasma carnitine concentrations were measured and found to be low. Total carnitine was $12 \mathrm{nmol} / \mathrm{ml}$ (normal values mean SD, $65(15) \mathrm{nmol} / \mathrm{ml}$ total carnitine and 40 (10) $\mathrm{nmol} / \mathrm{ml}$ free carnitine). At the beginning of November 1982 he was admitted with his worst attack so far. Vomiting persisted for a week and the muscle weakness progressed to the extent that he could not raise his head. Diplopia and dysphagia subsequently developed. The hepatomegaly became more pronounced and liver enzyme values rose sharply.

Total parenteral nutrition was begun and Lcarnitine $(100 \mathrm{mg} / \mathrm{kg} / \mathrm{day})$ was added. The boy's condition improved dramatically over the course of a few days. He was placed on a high carbohydrate diet with mid-chain triglycerides, gained weight, and the muscle weakness improved gradually. While on treatment the total carnitine plasma concentration was $73 \mathrm{nmol} / \mathrm{ml}$ with $69 \mathrm{nmol} / \mathrm{ml}$ free carnitine. A 12 hour fasting blood glucose value was still $60 \mathrm{mg} / \mathrm{dl}$ ( $3.3 \mathrm{mmol} / \mathrm{l})$, but blood ketone-body concentration was lower than an age matched control after a 12 hour fast. His acetoacetate and B-OH-butyrate values were $0.349 \mathrm{mmol} / \mathrm{ml}$ and $0.256 \mathrm{mmol} / \mathrm{ml}$ respectively, while the control had corresponding values of $0.704 \mathrm{mmol} / \mathrm{ml}$ and $0.613 \mathrm{mmol} / \mathrm{ml}$. The fasting test was not prolonged beyond 12 hours because of a recent report of sudden death after fasting in a patient with carnitine deficiency. ${ }^{4}$
The child has now been on carnitine treatment for 10 months and has not suffered any attacks; he has gained $7 \mathrm{~kg}$ in weight and feels very well. Muscle strength has now returned to normal. It should be noted that he still adheres to the meat-free diet.

\section{Discussion}

Since the first report of systemic carnitine deficiency in $1976,{ }^{5}$ more than 30 cases have been reported. Deficiency of carnitine blocks the mitochondrial oxidation of fatty acids to carbon dioxide in all tissues and to ketone bodies in the liver. Thus, patients who lack carnitine will become hypoglycaemic after a short period of starvation. Despite constant low carnitine concentrations, acute attacks of weakness and encephalopathy occur only intermittently. Whatever the exact exacerbating mechanism, it seems that most acute episodes are associated with fasting or semi-starvation. It is conceivable that mobilisation and uptake of free fatty acids in the face of a limited capacity for oxidation somehow have an initiating role. ${ }^{2}$

Exogenous carnitine is not usually needed for maintaining normal carnitine concentrations, as biosynthesis from lysine takes place. Carnitine is synthesised in the hepatocytes and released into the plasma for transfer to peripheral tissues. ${ }^{6}$ In human beings, carnitine may also be derived from the diet, and beer is a primary source. Vegetables contain a negligible amount of carnitine, and thus vegetarians have only endogenous carnitine. Newborns and infants are incapable of synthesising the necessary amount of carnitine and without exogenous carnitine, derived from milk products, symptoms of carnitine deficiency can occur. ${ }^{3}$

We believe that in our patient exogenous carnitine played an important role. Notwithstanding the impaired endogenous carnitine production, our patient, while on a regular diet, had sufficient carnitine to prevent recurring episodes of encephalopathy and the other signs of systemic carnitine deficiency. With the change to a vegetarian diet without meat and milk products, the amount of exogenous carnitine ingested was negligible, and frequent attacks occurring every two to three weeks resulted. The introduction of L-carnitine $(100 \mathrm{mg} /$ $\mathrm{kg}$ /day) increased the blood carnitine concentration to normal and despite the cohesiveness of the vegetarian diet, no further attacks have occurred over the past 10 months.

\footnotetext{
References

1 Engel AG, Angelini C. Carnitine deficiency of human muscle with associated lipid storage myopathy: a new syndrome. Science 1973;179:899-902.
} 
${ }^{2}$ McGarry JD, Foster DW. Systemic carnitine deficiency. N Engl Med 1980;303:1413-5.

${ }^{3}$ Slonim AE, Boram PR. Tanaka, et al. Dictary dependent carnitine deficiency as a cause of nonketotic hypoglycaemia in an infant. $J$ Pediatr 1981;99:551-6.

4 Parker D, Rott AW, Schimmel S, Andriola M, Di Manro S. Encephalopathy and fatal myopathy in two siblings. Am J Dis Child 1982;136:598-601.

${ }^{5}$ Boudin G, Mikol J, Guillerd A, Engel G. Fatal systemic carnitine deficiency with lipid storage in skeletal muscle, heart, liver and kidney. J Neurol Sci 1976;30:313-25.

${ }^{6}$ McGarry JD, Foster DW. Regulation of hepatic fatty acid oxidation and ketone body production. Annu Rev Biochem 1980;49:395-420.

Correspondence to Dr A Etzioni, Department of Pediatrics 'A', Rambam Medical Center, Haifa 35254, Israel.

Received 11 October 1983

\section{Fifty five years ago}

\section{A syndrome in the rat resembling pink disease in man}

RUBY O STERN (National Hospital, Queen Square, London)

'Investigation of the pathological changes occurring in young rats fed on dried egg-white shows that very characteristic changes occur in the central nervous system. These pathological changes still further emphasize the similarities of the condition in the rat to Swift's disease in man. These similarities may be thus briefly summarised:-

(i). Both diseases occur in young animals. Swift's disease has never been recorded in adults, while in the adult rat it is only after from three to five months that cutaneous lesions can be produced.

(ii). The diseases may occur on a diet of mothers' milk or a ration containing ample supplies of the known vitamins.

(iii). The clinical symptoms of both diseases are nutritional, nervous and cutaneous.

(iv). In rats there is a characteristic 'kangaroo' position, in children a knee-elbow position.

(v). In rats and children there is a curious mousy odour.

(vi). Death is often due to an intercurrent broncho-pneumonia.

(vii). There is no evidence that the diseases are due to an-infection with bacteria or ultramicroscopic viruses.

(viii). The pathological changes in the skin and nervous system are similar.' 